\title{
DEVELOPMENT AND RESEARCH OF NEW TECHNOLOGY FOR CLEANING DIESEL LUBRICATION SYSTEM
}

Valery Ostrikov $^{1}$, Victor Balabanov ${ }^{2}$, Valentin Safonov $^{3}$, Sergey Ishchenko $^{4}$

${ }^{1}$ State Scientific Institute All-Russia Research Institute on Use of Technics and Mineral Oil of Russian Academy of Agricultural Sciences, Russia; ${ }^{2}$ Russian Timiryazev State Agrarian University, Russia; ${ }^{3}$ Saratov State Agrarian University named after N.I. Vavilov, Russia; ${ }^{4}$ Primorsky State Agricultural Academy, Russia viitinlab8@bk.ru,vbalabanov@rgau-msha.ru,safonow2010sgau@yandex.ru, dir_nikolsk@mail.ru

\begin{abstract}
The refusal to carry out a washing operation of the lubrication system from pollution before replacing the used oil with fresh oil has a number of objective and subjective reasons. First of all, it is the high price of flushing oils, insufficient washing properties for flushing lubricating systems of diesel engines. As the result of the studies, it was found that flushing of the lubrication system and removal of contaminants from the oil channels can be carried out with used motor oil without draining it from the engine crankcase. It was determined that introduction of ammonium hydroxide into the used engine oil in a mixture with carbamide and subsequent engine operation at speeds of 1500-1600 rpm allows removing almost all types of contaminants from the oil. According to the basic physical and chemical characteristics, the oil purified in the engine meets the requirements for the base oils used in the production of flushing oils. In the process of cleaning used oil, partial cleaning of the engine oil channels is already taking place. At the next stage, additives of dimethyl sulfoxide, potassium isopropylate and diesel fuel are added to the cleaned oil in the crankcase. It was determined that the subsequent start of the engine and its idling with variable speeds for 30 to 40 minutes allow increasing compression in the cylinders, reducing the fuel consumption, and increasing the oil pressure in the lubrication system. As a result of subsequent operation of the engine after washing it with the proposed technological process and the composition of detergent additives, the service life of freshly refilled oil is increased.
\end{abstract}

Keywords: engine, lubrication system, cleaning, contamination, used engine oil, flushing oil, additives, compression, fuel consumption, oil pressure.

\section{Introduction}

During the operation of tractor engines, a significant amount of contaminants, wear products, resins accumulate in engine oil. Contaminants are also formed on the parts of the lubrication system, in the crankcase, oil channels, in the piston-cylinder group, etc. [1-7].

During the oil change operation, most of the contaminants are removed together with the used engine oil. However, it is practically very difficult to completely remove all contaminants from the lubrication system without the use of special technical equipment and flushing oils [5-7].

Due to the limited financial capabilities and unsatisfactory conditions of the material and technical base of the bulk of agricultural enterprises, the oils are replaced without washing the lubrication system.

At the same time, after changing the oil, after 5 to 8 hours of operation in the engine, the freshly refilled oil has a black colour.

The assertion that a sharp change in the colour of the oil from yellow to black is just a confirmation of the high washing properties of freshly refilled oil and does not bear any negative consequences, is not entirely true.

A sharp colour change in one way or another primarily indicates that resins and oxidation products appeared in the oil, and this has a negative effect on the further efficiency of the oil in the friction units and on its service life until the next change [5-7].

As the result of practical research, a sharp change in the colour of the oil is most often associated with the refusal, for one reason or another, from the washing operation and the fuel system.

Research and comparative analysis of the colour change and characteristics of motor oils after replacing and 89 hours of engine operation under conditions with and without preliminary washing of the lubrication system after draining the used oil was carried out at the State Scientific Institute AllRussia Research Institute on Use of Technics and Mineral Oil of Russian Academy of Agricultural Sciences (Fig. 1). 


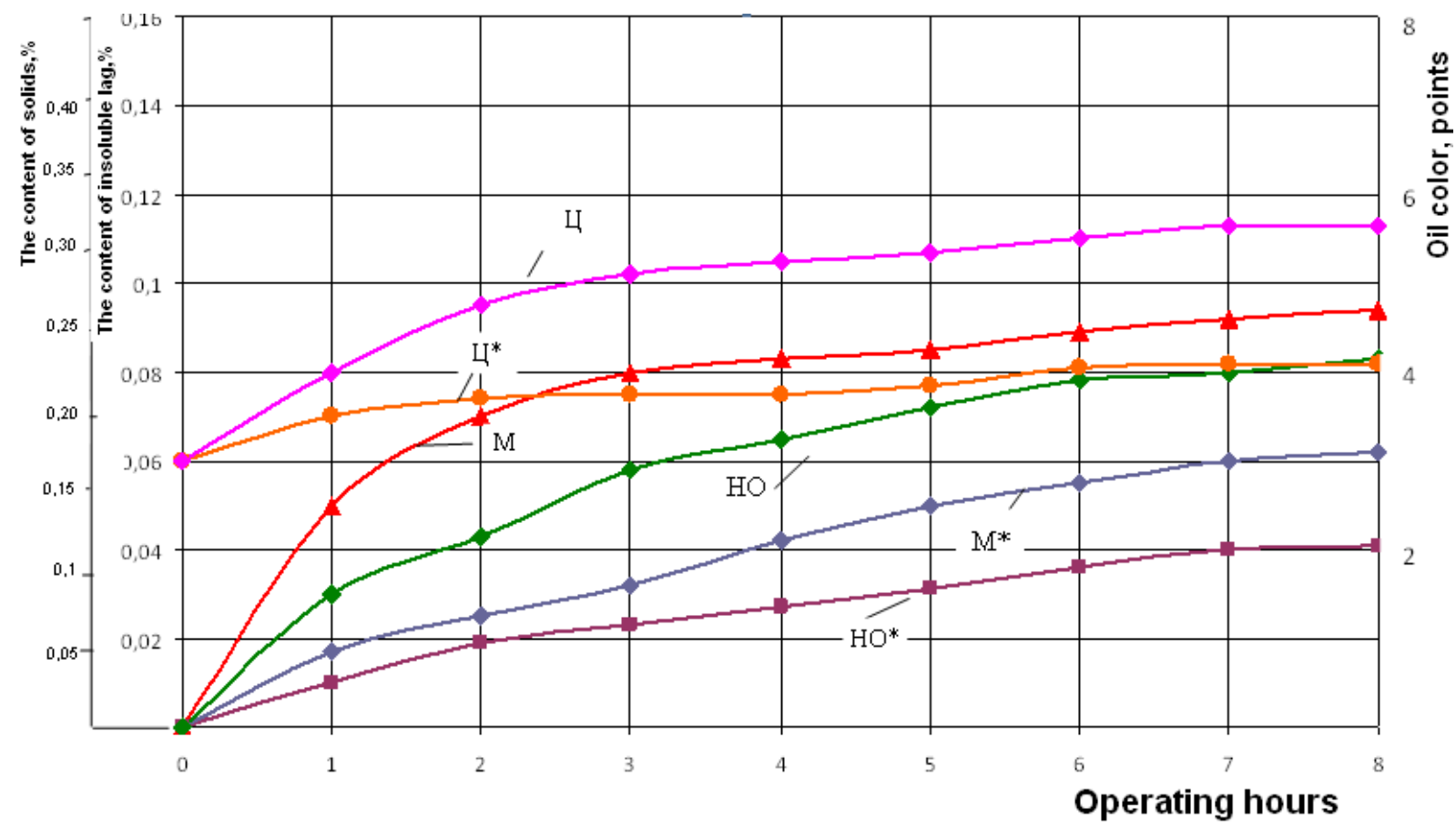

Fig. 1. Dependence of changes in the physicochemical characteristics of the engine oil on the operating time: without preliminary washing of the lubrication system and (*) with preliminary washing of the lubrication system

It was determined that the preliminary flushing of the lubrication system allows already after the first 8 hours of engine operation to predict a decrease in the oil life before replacement. The use of flushing oils in tractor engines is associated with high costs of flushing oils. If for flushing the lubrication system of a car engine 3 to 5 litres of oil are required, then for tractor engines 15 to 40 litres, depending on the brand.

The aim of the work is to increase the efficiency of tractor engines and reduce the maintenance costs.

Due to the limited financial capabilities of agricultural enterprises, the insufficient washing properties of flushing oils for cleaning from pollution and deposits of diesel engines, the task was to develop a resource-saving technology for flushing the lubrication system with exhausted motor oil with addition of additives [1-7].

\section{Materials and methods}

At the first stage, an operation is performed to clean the used engine oil from contaminants without draining it from the crankcase. For these purposes, the engine oil warms up to a temperature of $60-70{ }^{\circ} \mathrm{C}$. Then, through the filler neck (the engine is inoperative), a mixture of ammonium hydroxide with urea is introduced into the oil in a percentage ratio of $0.5-1.0 \%$ by weight to the volume of oil in the crankcase. The engine starts and idles for 5-7 minutes. After that, the engine speed is increased to $1500-1600 \mathrm{rpm}$, and the engine continues to run for 30-40 minutes. Every 5 minutes, a drop of oil is removed with a dipstick and placed on filter paper. The chromatogram of the oil stain determines the effectiveness of oil cleaning. After changing the colour of the oil stain from black to yellow, the engine stops. Dismantling and cleaning of the centrifuge for cleaning the oil, built into the lubrication system.

\section{Results and discussion}

At the next stage, an oil concentrate is prepared, consisting of oil purified in the engine, $1 \%$ of the mass, diesel fuel $2 \%$ of the mass, dimethyl sulfoxide $2 \%$ of the mass, potassium isopropylate $2 \%$ of the mass. The mixture is mixed and placed through the filler neck into the crankcase. Next, the engine starts and runs 3-5 min at 500-600 rpm. At the end of the mixing process, the revolutions 
increase to $1200-1500 \mathrm{rpm}$ and the engine runs $30-40 \mathrm{~min}$ with a periodic sharp decrease in revolutions to min and increase to max.

Figure 2 shows the dependence of the change in the content of insoluble sediment of oil and colour during operation of the engine with the flushing composition.

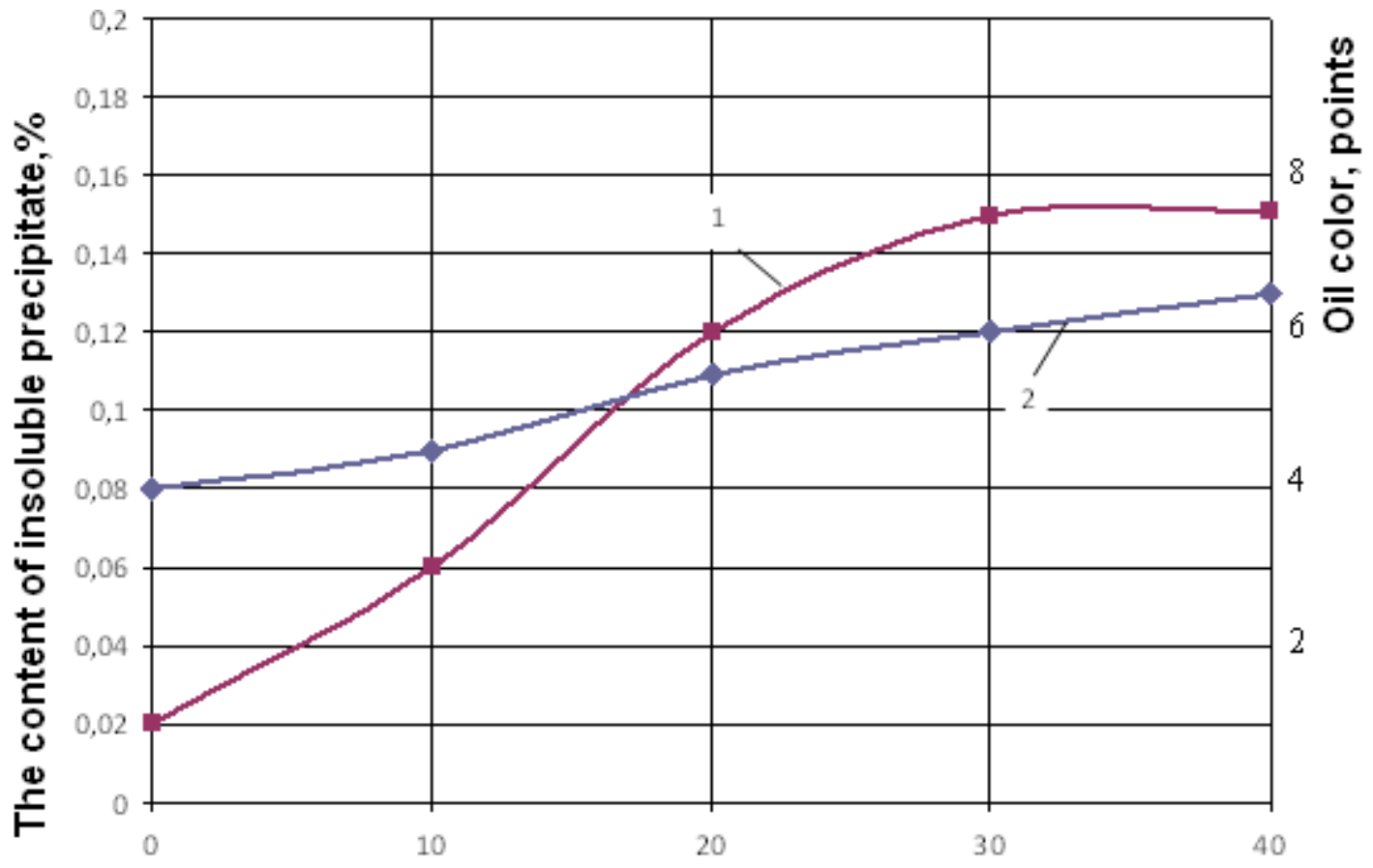

Engine operating time, min

Fig. 2. Dependence of changes in the content of insoluble precipitate (1) and oil colour (2) on the time of engine operation

Analyzing the obtained dependence, the impurity content in the oil was found to be $0.02 \%$ after the first stage of purification. With further work in the oil engine with additives, the content of insoluble sediment (resins, asphaltenes, etc.) increased and reached $0.15 \%$ by $30 \mathrm{~min}$. The colour of the purified oil changed from 4 to 6.5 points in units of CNT.

The results obtained indicate sufficiently high washing properties of the experimental composition of the flushing oil.

Before and after the washing operation of the lubrication system to assess the operational properties of the developed technological process of washing the composition of the washing oil was determined by the compression in the cylinders and fuel consumption.

Table 1 presents the results of the evaluation of the characteristics of the D-240 engine.

Table 1

Characteristics of the D-240 engine

\begin{tabular}{|l|c|c|}
\hline \multicolumn{1}{|c|}{ Indicators } & $\begin{array}{c}\text { Prior to } \\
\text { flushing operations in } \\
\text { lubrication systems }\end{array}$ & $\begin{array}{c}\text { After } \\
\text { flushing operations in } \\
\text { lubrication systems }\end{array}$ \\
\hline $\begin{array}{l}\text { The average value of compression in the } \\
\text { cylinders, } \mathrm{kgf} \cdot \mathrm{cm}^{-3}\end{array}$ & 18 & 22 \\
\hline Fuel consumption, $\mathrm{l} \cdot \mathrm{h}^{-1}$ our & 14 & 10.5 \\
\hline $\begin{array}{l}\text { Oil pressure in the lubrication system, } \\
\mathrm{kgf} \cdot \mathrm{cm}^{-2}\end{array}$ & 1.9 & 3.0 \\
\hline
\end{tabular}

It was found that flushing the lubrication system with the developed method allows to increase the engine performance and reduce the cost of the fuel used. 
To confirm the proposed assumptions about the influence of the flushing operation of the lubrication system on the life of the engine oil, a comparative analysis of the changes in the basic physical and chemical characteristics of the oil over the next 250 hours of operation was carried out.

Figure 3 shows the dependences of the change in viscosity $v$, contamination content of insoluble precipitate (IP), \%, alkaline number (AN), $\mathrm{mg} \mathrm{KOH} \cdot \mathrm{g}^{-1}$. of fresh oil (M-10G2) on the operating time in the engine without washing and with washing the lubrication system.

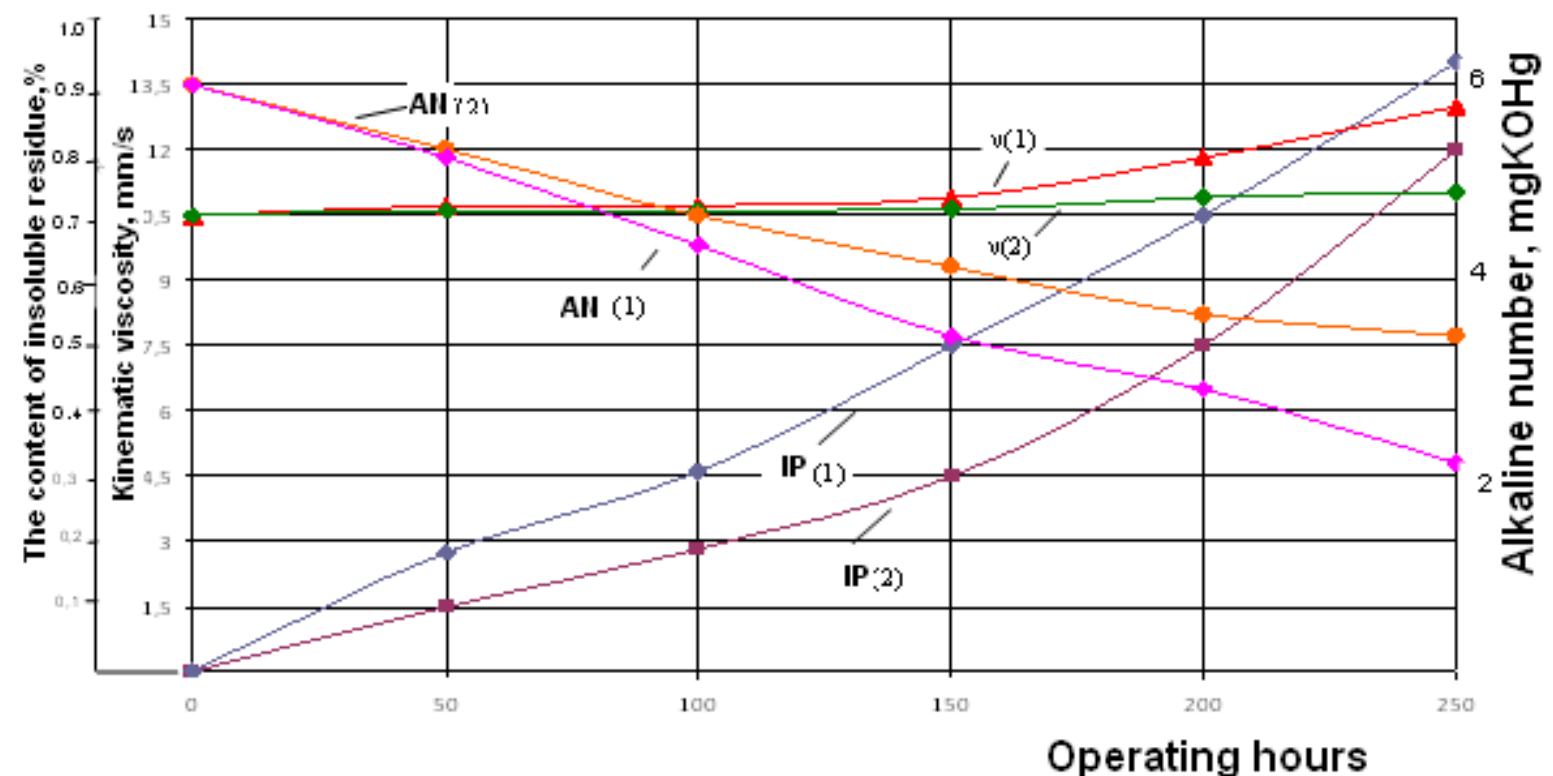

Fig. 3. Dependence of changes in physico-chemical characteristics of motor M-10G2 oils in the tractor engine: without preliminary flushing of the system lubricants (1); flushing the lubrication system (2)

Analyzing the obtained dependences, it should be noted that during the washing operation of the tractor engine ICE lubrication system, the oil viscosity $v(2)$ at the time of replacement (running time 250 hours) was $10.5 \mathrm{~mm}^{2} \cdot \mathrm{s}^{-1}$, and in the oil that worked in the engine, where the washing before changing was not carried out, $v(1)=11.5 \mathrm{~mm}^{2} \cdot \mathrm{s}^{-1}$.

The increase in the viscosity $v(1)$ occurred gradually with an increase in the operating time due to the accumulation of impurities and IP resins (1).

The alkaline number of motor oil characterizes to a certain extent the detergent content dispersing, antioxidant, antiwear, extreme pressure and antifriction additives in the oil.

Considering the change in the alkaline number in oils, it should be noted that in the engine that was running without flushing the lubrication system by 200 hours of operation this indicator had a practically defective value of $2.1 \mathrm{mg} \mathrm{KOH} \cdot \mathrm{g}^{-1}$, while in the engine running on the same oil and under similar operating conditions and technical condition $3.5 \mathrm{mg} \mathrm{KOH} \cdot \mathrm{g}^{-1}$ to 250 hours of operation. That is, it can be argued that the oil had a fairly high margin of efficiency.

\section{Conclusions}

1. The work presents a new resource-saving technology for cleaning the engine lubrication system with used motor oil using a complex of special cleaning additives.

2. The studies of the physicochemical characteristics of engine oil show that the developed technological process for cleaning the lubrication system allows increasing compression in the engine cylinders and reducing the cost of its subsequent operation.

3. The developed technology allows to extend the life of the oil until replacement, to solve the problem of efficient use of used motor oils. 


\section{References}

[1] Strebkov S.V., Streltsov V.V. The use of fuel, lubricants and industrial fluids in the agricultural sector: a training manual. - Belgorod: BSAA, 1999 .- 404 p. (In Russian).

[2] Nosov A.O. Increasing the efficiency of operation of automotive diesel engines by improving the prevention of the lubricant system/The dissertation for the degree of candidate of technical. Sciences, Saratov, 2013 .- $118 \mathrm{p}$.

[3] Beklemyshev V.I., Makhonin I.I., Lepgov A.F. and others. The influence of organometallic additives RENOM on the friction surface and indicators of automotive technology // Herald of mechanical engineering. 2004. No. 10. pp. 51-55. (In Russian).

[4] Balabanov V.I. Improving the quality of repaired internal combustion engines by implementing selective transfer during friction // Vestnik mashinostroeniya, 2001. No. 8. pp. 14-19. (In Russian).

[5] Kartoshkin A.P. The study of deposits on the details of the cylinder-piston group during the operation of agricultural tractor diesel engines. L.: LSI, 1984. 97 p. (In Russian).

[6] Ostrikov V.V., Petrashev A.I., Sazonov S.N., Zabrodskaya A.V. Fuel, lubricants and technical fluids: a training manual./Moscow - Vologda: Infra - Engineering, 2019 .- 244 p. (In Russian).

[7] Salmin V.V. Evaluation of the operational properties of motor oils // Mechanization and Electrification of Agriculture. - 2003. - No. 7. - p. 18 (In Russian). 